\title{
Designing Technologies for Playful Interspecies Communication
}

\author{
Fiona French \\ London Metropolitan University \\ London, England \\ f.french@londonmet.ac.uk
}

\author{
Ilyena Hirskyj-Douglas \\ Aalto University \\ Helsinki, Finland \\ ilyena.hirskyj-douglas@aalto.fi
}

\author{
Heli Väätäjä \\ Lapland University of Applied \\ Sciences \\ Lapland, FI \\ heli.vaataja@lapinamk.fi
}

\begin{abstract}
This one-day workshop examines how we might use technologies to support design for playful interspecies communication and considers some of the potential implications. Here we explore aspects of playful technology and reflect on what opportunities computers can provide for facilitating communication between species. The workshop's focal activity will be the co-creation of some theoretical systems designed for specific multi-species scenarios. Through our activities, we aim to pave the way for designing technology that promotes interspecies communication, drawing input not only from ACI practitioners but also from those of the broader HCI and animal science community, who may be stakeholders in facilitating, expanding, and/or redefining playful technology.
\end{abstract}

\section{KEYWORDS}

Playful technology; Animal Computer Interaction; interspecies play; interspecies communication; game design; animal play; social play.

\section{ACM Reference format:}

Fiona French, Ilyena Hirskyj-Douglas and Heli Väätäjä. 2020. Designing Technologies for Playful Interspecies Communication. In Proceedings of International Animal-Computer Interaction conference. (ACI'20). ACM, London, UK. 6 pages. https://doi.org/10.1145/1234567890

\section{Introduction}

Animals, including humans, have desires to interact with each other (within species and inter-species) in energetic and playful ways [22]. Play itself is a social activity involving communication, intention, role playing, rules and cooperation [2]. Play also impacts the development of cognitive, psychological, and social skills. Additionally, as play seems to introduce and increase uncertainty, it creates new challenges for the animals involved, including the human ones [21].

\footnotetext{
*Article Title Footnote needs to be captured as Title Note

tAuthor Footnote to be captured as Author Note

Permission to make digital or hard copies of part or all of this work for personal or classroom use is granted without fee provided that copies are not made or distributed for profit or commercial advantage and that copies bear this notice and the full citation on the first page. Copyrights for third-party components of this work must be honored. For all other uses, contact the owner/author(s). Animal-Computer Interaction'20, November, 2020, Milton Keynes, UK.

(C) 2018 Copyright held by the owner/author(s). 978-1-4503-0000$0 / 18 / 06 \ldots 15.00$

https://doi.org/10.1145/1234567890
}

Moreover, play has positive effects on flexibility, and coping with stress [21]. Play itself as an activity is characterized by voluntary engagement, and by being positively reinforcing; meaning that the players find it pleasurable [4] [23]. Play also involves positive emotions and feelings and intense behavioural performances, which have been observed in numerous species.

We note that social play is an important aspect of communication not only within species, but also between species, creating opportunities to encourage and enhance social relationships, promote affective connectedness and bonding, and foster a deeper understanding of the play partner's intentions, reactions, and behaviours. However, this does not mean that all play is inherently good. We know that captive animals may exhibit stereotypic behaviour when stressed, which might correlate to compulsive use of a new toy. Recently, the World Health Organisation recognised gaming addiction (in humans) as a new kind of disease. This highlights the importance of enabling and encouraging a balanced lifestyle for all species.

Furthermore, Somerville et al. [27] point out that domestic dogs playing with humans are likely to have been shaped by artificial selection in order to promote this trait, and that play is not a reliable positive welfare indicator but depends on the context. We have characterised play as being voluntary, but the human-dog dynamic suggests that usually the human is in control of when and how play occurs. Yamanashi et al. [34] are similarly hesitant to associate social play between adult chimps as showing positive welfare, as it tends to occur in tense situations (e.g. before feeding). This contrasts with mutual grooming behaviour, which always indicates affiliation between the animals. We therefore need to recognise and explore also the subtle power dynamics that may occur within playful situations.

The workshop provides a platform for both ACI and non-ACI researchers to re-evaluate the current animal playful technology landscape, as well as foster future potential collaborations where theoretical and empirical interests overlap or complement each other. The workshop forms a timely addition to the ACI field as more playful systems flood the consumer market and playful technology becomes further embedded within our homes. 
The aims of this ACI workshop at ACI'20:

(i) to ideate on how different species could play together (thereby communicating) facilitated by technologies;

(ii) to consider how this might be managed;

(iii) to reflect on how ethics, autonomy and the role of power might play out in future playful systems.

The output of this workshop is a preliminary framework for playful interspecies communication, and a set of designs addressing this theme and their embodied surrounding issues. These outputs can provide a basis for future design and research activities, while also grounding the discussion about technology mediated animal play.

\section{Background}

The field of Animal Computer Interaction (ACI), which deals explicitly with the intersection of animals with technology, has now been established for almost a decade, building from the original ethos and goals drawn within the ACI Manifesto [18] [14]. ACI encapsulates a broad range of purposes where animals take on different roles in technology systems. The animals within these contexts span from those that we keep in zoos and sanctuaries [29] to domesticated animals, such as pets and farm animals [15] [5] and animals in the wild [17].

Increasingly, there is a trend in ACI towards creating playful systems. Within this scope, definitions have been given for playful interfaces [25] as well as methods emerging for both the design of systems by humans [9] and designing with the target species [30] [8] [32]. Pons et al. [24] define playful technologies as 'animal-centered ecosystems with intelligent capabilities which is able to learn from the animals' behaviors and interactions, using the acquired knowledge to adapt itself to the context'. Yet, as Asplin [1] notes, definitions such as these in ACI have often become narrow, focusing on the interaction with the interface. Therefore, here we define playful technologies as computer systems which enable playful behaviours for animal and human entities.

Drawing back to play, we understand that three types of animal play are commonly recognised - social, locomotor and object play [4] [3]. Social play has been seen to help animals learn social rules; locomotor play may promote fitness and agility; object play offers cognitive and sensory enrichment [28]. We suggest that social play is a valid form of engagement, forming a potentially non-verbal communication between participants and fostering a deep understanding of the other - within the 'magic circle' of play [13].
ACI has experimented in facilitating cross-species communication and social play over several years, often using playful techniques between humans and non-human animals [32] and between non-human animals themselves [16]. Much of this research has been conducted with mammals that are known to have sophisticated communication skills. For example, Wirman [32] designed a touch-screen game interface for captive orangutans, aiming to raise awareness of their wellbeing and facilitate cross-species communication (with humans). The device successfully promoted playful interactions between human and orangutan participants but failed in engaging the animals successfully with the interface. The Cetacean Hearing and Telemetry system designed by Herzing et al. [12] was an underwater keyboard interface that dolphins could use for visual and acoustic signalling. Its goal was to enable dolphins to learn new (whistle-based) signals and to use them to communicate with humans. Drawing from this, Pons et al [26] developed a remote interspecies experience aimed at hospitalised children and dogs in daycare, whereby a child could control a robot (sphero) ball and watch a dog play with it. However, like Wirman's system, these technologies were successful in facilitating human-animal communication only when humans were actively engaged where it was uncertain and often did not seem like the animals were having meaningful interactions [26].

To facilitate interspecies play, many of these playful systems in ACI use toys. The autotelic nature of play means that an interactive toys have the potential to be very useful for exploring species-specific modes of interaction, in that theoretically there needs to be no coercion or training required for the animal to engage with the device [32] [24]. In fact, an explicit introduction to a playful scenario may be counterproductive, in that it then becomes difficult to interpret the animal's motivations for engaging. Developing these ideas, Wirman and Zamansky [33] emphasised that in order for 'playful ACI' to take place, the animal had to be in a relaxed state, directing its behaviour towards the playful device, and interacting with the device control system so as to activate some kind of output. They pointed researchers to specific issues regarding such devices - such as identifying the associated stimuli and potential rewards, recording all possible responses from the animal, analysing the impact on the animal's physical and emotional states and taking into account both the context and methods for introducing novel devices.

There still remains for ACI practitioners an ongoing challenge relating to how humans can communicate, design with/for and build playful systems with users who belong to a different species. The problem in design and communication is further complicated with animals when it is not possible to ask appropriate questions or reliably interpret signals. Thus some designers have attempted versions of Research through Design 
and iterative prototyping for developing versions of their designs [10] [29] [30], while other designers have turned to imaginative methods that rely upon speculation in order to creatively move forward. This latter approach builds spaces for debates and discussions as an alternative way of being the 'other', and to inspire and encourage the future designs with animals [6] [16]. Lawson et al. [11], North [20] and HirskyjDouglas \& Lucero [16] have all used design fiction to speculate about the inner lives of animals. Equally, North has created physical devices that aim to support humans' understanding of animals through wearables that re-create an animal's communication through horse ears. These concepts emphasised the simulated embodiment of the other as a means to gain insight.

The overarching question all these methods, technologies and design scopes raise is how might we use technology to bridge the gaps between diverse users and provide a shared experience, using a playful framework to support cooperation and engagement?

Multi-disciplinary ideation has been shown to be a useful method for developing future concepts for animaltechnologies, due to the many unknowns in this new field of research [7]. As it is not currently possible to ask non-human users how, when or with what they would like to play, far less what playful technology they might find interesting, we can only imagine systems that might be suitable, and the more diverse perspectives and expert knowledge we can bring to this task, the richer the probable design outcomes. We anticipate that the act of designing these imaginary systems will open up the research problem within interspecies play by raising questions and framing the research in a narrative that is easy for other people to understand.

\section{Workshop Questions}

- What characteristics of playful communication can be leveraged by technology in an interspecies playful context?

- What issues arise when designing for playful interspecies communication including ethical, appropriate and equal participation? ${ }^{1}$

- How can design ideation support creating playful interspecies communication?

\section{Agenda}

Prior to the workshop there will be a pre-questionnaire online to frame how the participants view interspecies communication and playfulness. Before the workshop, these contributions will be shared via our website to enable participants to view and learn others' perspectives on our topic. Participants will also be required to put forward one paper upon our topic commenting upon the playfulness, interspecies communication and how technologies mediated this. We will then create a library of readings to further situate participants.

\subsection{During the Workshop}

Our workshop will be held online through Discord/Slack and Zoom. We will begin by using Zoom to offer a short presentation sharing our findings collated from the prequestionnaire, during which we invite participants to raise any questions that arise which will be noted in our Miro workspace $^{2}$. From the questions raised during the preworkshop, the organisers will have formed an initial outline of what interspecies technology mediated play means to different perspectives. This discussion will begin the start, and ground, the workshop.

Following from this, for the main design tasks participants will be allocated to predefined diverse groups (of around 3-5 people), based on background, expertise and interests. We will provide a series of relevant challenges related to particular interspecies situations. For these tasks we will give people cards with different animals on, and another set of cards with types of play and ask people to draw two animal cards and a play card and speculate how this interspecies play might look. Groups then work together remotely on Miro to brainstorm, share and discuss concepts with the purpose of generating some plausible, probable, or preferable designs [6]. We will have additional online whiteboards, storyboard templates and Discord or Slack channels per group to allow both sketching, storyboarding and writing as a mixed method approach.

We will schedule regular breaks and use playful approaches, such as optional games, to provoke discussions. At regular intervals, groups will be given a wildcard that suggests a new lens for interrogating their design. We will also enable movement across teams to help build critical reflections from different perspectives and vantages.

The co-created designs will then be shared with the group, with authors explaining the viewpoints held within their designs. In this phrase, we aim for structured and semi-structured discussions and friendly critical review leading to the identification of key features relating to playful technologies within an ACI scope.

\section{Workshop Output}

\footnotetext{
1 Shared readings: https://docs.google.com/spreadsheets/d/1cNaiuZxlqbr4mUy1oZVaP1n_6qH6ImBahNbECgOtowI/edit?usp=sharing

2 Questionnaire: https://forms.gle/YLJdYmgP3FbNBt6Q6
} 
We aim for this workshop to be a beginning of a series of workshops focusing on the topic of playful interspecies communication. As the issues are too many to be solved within one instance, this will allow for a continued delineation and development of our topic. The outcomes of workshops include heightened sensitivity to new issues, joint publications and research programs, and critical yet friendly feedback on emerging ideas. Beyond publications/workshops we have the following outputs:

Output \#1: On the workshop website we will present the key discursive themes, in the form of questions raised, to facilitate discussion of the topic of playful interfaces for communication with animals across disciplines.

Output \#2: Online open publication of a series of co-created design ideations for technology-enabled playful inter-species communication systems, accessed on the workshop website.

Output \#3: Crowd-sourced list of readings published on the workshop website.

\section{ATTENDEES}

In order to publicise the workshop, we will circulate a call via the appropriate channels, including mailing lists, ACI blogs and Facebook groups, and social media. We anticipate that the attendees will comprise a broad range of people, including those who are curious about the research area and those who have been involved for several years. Attendees will share an openness to discuss the issues outlined above and a willingness to collaborate with experts from other areas. To facilitate this, we invite both ACI and non-ACI practitioners to join the workshop and the overarching discussions. We will target those from animal ethology, game design and research, system engineering and animal-robotics, while also welcoming those from relevant industries (pet products, for example).

To be as inclusive as possible, this workshop will be offered as a virtual event. We will take all attendees' time zones into account and plan accordingly. The workshop experience will also include many breaks with opportunities to socialise, discuss and play games with each other. The number of participants in the workshop is limited to 20. The participants will be selected based on their contribution statements in the pre-workshop questionnaire.

\section{Organisers}

All of the organisers have published within the ACI field on the topic of playful interfaces, approaching this topic in various ways.
Fiona French is course leader for BSc Games Programming at London Metropolitan University. Her research interests include Animal Computer Interaction, physical computing, and toy and game design and development. Fiona has recently been investigating the design of playful interactive systems for elephants. She has organised several gamejams and other play related public events, including three ZooJams at recent ACI conferences [7].

Dr. Ilyena Hirskyj-Douglas's research looks at designing methods for animals from the standpoint of what this interaction means, and how we measure animals' usage of implemented devices towards a participatory and co-design manner. She has previously published articles on speculative designing with animals [16] and questioning what it means to design with/for animals [15]). She is interested in interspecies communicative play from an animal-animal perspective towards how computers can facilitate this.

Dr. Heli Väätäjä studies in the field of ACI the use of technology to enhance animal welfare and the human-animal bond, and to understand animal behaviour and emotions. She has organized several workshops in conferences, for example, in ACI 2017 on Technology for Bonding in Human-Animal Interaction. She has published over 80 peer-reviewed articles in conferences, books, and journals. She also tests cognitive abilities of dogs ( $>300$ tested dogs of various breeds) and is qualified as an expert in behaviour analysis-based animal training.

\section{Draft Call}

The following is a draft call for the workshop's website (Playful Communication):

Designing for Interspecies Playful Communication is a oneday workshop running on the first day of ACI 2020 on the Xth November 2020.

ACI investigates animals in computer systems and situations. Whilst in the field of Human Computer Interaction (HCI) playful design has become a common terminology, in animal systems what this means is still relatively undefined. This workshop aims to explore what playful interfaces might mean for animals, and how multiple species can communicate through/with/via technologies for play. We welcome participants from a variety of disciplines to come and discuss what it means to playfully communicate within animals in a computer system, and how animals are positioned within these. During the workshop, attendees will discuss key questions, such as types of play we can support, how humans and their computer systems can facilitate this, and what different design approaches we can make towards mapping this research space. 


\section{REFERENCES}

[1] Fredrick Asplin. 2020. Unleashing Animal-Computer Interaction: A Theoretical Investigation of the "I" in ACI. PhD Thesis.

[2] Marc Bekoff and Colin Allen. 1998. Intentional communication and social play: How and why animals negotiate and agree to play. In Animal PlayEvolutionary, Comparative, and Ecological Perspectives.

[3] Marc Bekoff, John Alexander Byers. 1998. Animal play: Evolutionary, comparative and ecological perspectives. Cambridge University Press: Cambridge, UK. 97-114.

[4] Gordon M. Burghardt. 2005. The Genesis of Animal Play: Testing the Limits; MIT Press: Cambridge, MA, USA. 501

[5] Adrian D. Cheok, Roger Thomas Kok Chuen Tan, Roshan Lalintha Peiris, and Owen Noel Newton Fernando, Imiyage Janaka Prasad Wijensena, Janyn Yin Ping Sen. 2011. Metazoa ludens: mixed-reality interaction and play for small pets and humans. IEEE Trans. Syst. Man. Cybern.-Part A Syst. Hum. 41(5), 876-891 (2011).

[6] Anthony Dunne and Fiona Rabby. 2013. Speculative Everything: Design, Dreaming, and Social Dreaming. MIT Press Cambridge.

[7] Fiona French, Sofya Baskin, Reinhard Gupfinger, Sarah Webber, and Anna Zamansky. 2019. ZooJamming: Designing Beyond Human Experience. Paper at ICGJ 2019 (International Conference on Game Jams, Hackathons and Game Creation Events) March 2019, San Francisco, USA. https://doi.org/10.1145/3316287.3316294

[8] Fiona French, Clara Mancini, and Helen Sharp. 2015. Designing Interactive Toys for Elephants. In Proceedings of the 2015 Annual Symposium on ComputerHuman Interaction in Play (CHI PLAY '15). Association for Computing Machinery, New York, NY, USA, 523-528. DOI: https://doi.org/10.1145/2793107.2810327 [9] Fiona French, Sofya Baskin, Billy Wallace, Adrian David Cheok, Anna Zamanzky, and Eleonora Nannoni. 2017. FarmJam 2017: Designing Enrichment for Farm Animals. In Proceedings of the Fourth International Conference on Animal-Computer Interaction (ACI2017). Association for Computing Machinery,

New York, NY, USA, Article 21, 1-6. DOI: https://doi.org/10.1145/3152130.3152154

[10] Fiona French, Clara Mancini, and Helen Sharp. 2017. Exploring Research through Design in Animal Computer Interaction. In Proceedings of the Fourth International Conference on Animal-Computer Interaction (ACI2017) Association for Computing Machinery, New York, NY, USA, Article 2, 1-12. DOI: https://doi.org/10.1145/3152130.3152147

[11] Shaun Lawson, Ben Kirman, and Conor Linehan. 2016. Power, participation, and the dog internet. interactions 23, 4 (July - August 2016), 37-41. DOI: https://doi.org/10.1145/2942442

[12] Denis L. Herzing. 2016. Interfaces and keyboards for human-dolphin communication: What have we learned. Animal Behavior and Cognition, 3(4), pp.243-254.

[13] Johan Huizinga. 1955. Homo Ludens. A Study of the Play Element in Culture, trans. by R.F.C. Hull, Boston: Beacon (1938).

[14] Ilyena Hirskyj-Douglas, Patricia Pons, Janet C. Read, and Javier Jaen. 2018. Seve $\mathrm{n}$ years after the manifesto: Literature review and research directions for technologies in animal computer interaction. Multimodal Technologies and Interaction 2, no. 2 (2018): 30.

[15] Ilyena Hirskyj-Douglas, Janet C. Read, and Brendan Cassidy. 2017. A dog centred approach to the analysis of dogs' interactions with media on TV screens." International Journal of Human-Computer Studies 98 (2017): 208-220.

[16] Ilyena Hirskyj-Douglas and Andrés Lucero. 2019. On the Internet, Nobody Knows You're a Dog... Unless You're Another Dog. In Proceedings of the $2019 \mathrm{CHI}$ Conference on Human Factors in Computing Systems (CHI '19). Association for Computing Machinery, New York, NY, USA, Paper 117, 1-12. DOI: https://doi.org/10.1145/3290605.33003479

[17] Hiroki Kobayashi, Kana Muramatsu, Junya Okuno, Kazuhiko Nakamura, Akio Fujiwara, and Kaoru Saito. 2015. Playful rocksalt system: animal-computer interaction design in wild environments. In Proceedings of the 12th International Conference on Advances in Computer Entertainment Technology (ACE '15). Association for Computing Machinery, New York, NY, USA, Article 62, 1-4. DOI: https://doi.org/10.1145/2832932.2837012

[18] Clara Mancini. 2011. Animal-computer interaction: a manifesto. interactions 18, no. 4 (2011): 69-73.

[19] Steve North. 2017. Hey, where's my hay? design fictions in horse-computer interaction. In Proceedings of the Fourth International Conference on AnimalComputer Interaction (ACI2017). Association for Computing Machinery, New York, NY, USA, Article 17, 1-5. DOI: https://doi.org/10.1145/3152130.3152149 [20] Steve North. 2019. Imaginary Studies: A Science Fiction Autoethnography Concerning the Design, Implementation and Evaluation of a Fictional Quantitative Study to Evaluate the Umamimi Robotic Horse Ears. In Extended Abstracts of the 2019 CHI Conference on Human Factors in Computing Systems (CHI EA '19).
Association for Computing Machinery, New York, NY, USA, Paper alt03,1-11. DOI: https://doi.org/10.1145/3290607.3310428

[21] Elisabetta Palagi. 2018. Not just for fun! Social play as a springboard for adult social competence in human and non-human primates. Behav Ecol Sociobiol 72, 90 (2018). https://doi.org/10.1007/s00265-018-2506-6

[22] Jaak Panksepp. 2005. Affective consciousness: Core emotional feelings in animals and humans. Consciousness and cognition, 14(1), 30-80.

[23] Sergio Pellis, and Vivien Pellis. 2013. The playful brain: venturing to the limits of neuroscience. Simon and Schuster.

[24] Patricia Pons, Javier Jaen, and Alejandro Catala. 2014. Animal Ludens: Building Intelligent Playful Environments for Animals. In Proceedings of the 2014 Workshops on Advances in Computer Entertainment Conference (ACE '14 Workshops). Association for Computing Machinery, New York, NY, USA, Article 3, 1-6. DOI: https://doi.org/10.1145/2693787.2693794

[25] Patricia Pons, Javier Jaen and Alejandro Catala. 2015. Envisioning Future Playful Interactive Environments for Animals. In More Playful User Interfaces; Nijholt, A., Ed.; Springer: Singapore, 2015; pp. 121-150.

[26] Patricia Pons, Alicia Carrion-Plaza and Javier Jaen. 2019. Remote interspecies interactions: Improving humans and animals' wellbeing through mobile playful spaces. Persvasive and Mobile Computing. Vol 52 112-130.

[27] Sommerville, R., O'Connor, E. A., \& Asher, L. (2017). Why do dogs play? Function and welfare implications of play in the domestic dog. Applied animal behaviour science, 197, 1-8.

[28] Marek Spinka, Ruth C. Newberry, and Marc Bekoff. 2001. Mammalian play: training for the unexpected. The Quarterly review of biology 76, no. 2 (2001): 141-168.

[29] Sarah Webber, Marcus Carter, Wally Smith, Frank Vetere. 2017. Interactive technology and human-animal encounters at the zoo, International Journal of Human-Computer Studies, Volume 98, 2017, Pages 150-168, ISSN 1071-5819, https://doi.org/10.1016/j.ijhcs.2016.05.003.

[30] Michelle Westerlaken and Stefano Gualeni. 2016. Becoming with: towards the inclusion of animals as participants in design processes. In Proceedings of the Third International Conference on Animal-Computer Interaction (ACI '16). Association for Computing Machinery, New York, NY, USA, Article 1, 1-10. DOI: https://doi.org/10.1145/2995257.2995392

[31] Michelle Westerlaken and Stefano Gualeni. 2014. Grounded Zoomorphism: An Evaluation Methodology for ACI Design. In Proceedings of the 2014 Workshops on Advances in Computer Entertainment Conference (ACE '14 Workshops). Association for Computing Machinery, New York, NY, USA, Article 5, 1-6. DOI: https://doi.org/10.1145/2693787.2693796

[32] Hanna Wirman. 2014. Games for/with strangers-Captive orangutan (pongo pygmaeus) touch screen play. Antennae.

[33] Hanna Wirman \& Anna Zamansky. 2016. Toward characterization of playful ACI. interactions, 23(4), 47-51.

[34] Yamanashi, Y., Nogami, E., Teramoto, M., Morimura, N., \& Hirata, S. (2018) Adult-adult social play in captive chimpanzees: Is it indicative of positive animal welfare?. Applied Animal Behaviour Science, 199, 75-83. 